\title{
Téoros
}

Revue de recherche en tourisme

\section{Tourisme culturel}

\section{Faux dilemmes et vraies questions}

\section{André Dudemaine}

Volume 17, numéro 2, été 1998

L'industrie touristique autochtone

URI : https://id.erudit.org/iderudit/1072269ar

DOI : https://doi.org/10.7202/1072269ar

Aller au sommaire du numéro

Éditeur(s)

Université du Québec à Montréal

ISSN

0712-8657 (imprimé)

1923-2705 (numérique)

Découvrir la revue

\section{Citer cet article}

Dudemaine, A. (1998). Tourisme culturel : faux dilemmes et vraies questions. Téoros, 17(2), 17-19. https://doi.org/10.7202/1072269ar d'utilisation que vous pouvez consulter en ligne.

https://apropos.erudit.org/fr/usagers/politique-dutilisation/ 


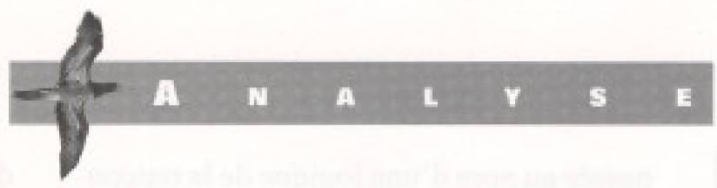

\section{TOURISME CULTUREL}

\section{FAUX DILEMMES ET VRAIES QUESTIONS}

\section{André Dudemaine}

On a d'ores et déja identifié plusieurs obstacles au développement du tourisme en milieu amérindien et inuit, tels l'éloignement, le manque d' infrastructures d'accueil, l'absence de produits touristiques adaptés aux besoins du marché international. Il est certainement heureux que s'entreprenne aujourd' hui, dans le cadre d'une revue universitaire, une discussion approfondie de la question. On trouvera dans les lignes qui suivent les reflexions d'un praticien de l'animation culturelle qui seront de nature à alimenter la réflexion qui s'amorce sur le sujet dans les milieux spécialisés. Cet article devrait donc faire avancer la discussion en identifiant un certains nombre de faux problèmes qui resurgissent chaque fois qu'on aborde le sujet du tourisme dit culturel : le supposé désenchantement qui attendrait les touristes d'outre-mer en visite chez l'une ou l'autre des Premières nations du Québec et les relations entre la métropole (où l'on trouve un nombre important d'autochtones urbains) et les régions (où se trouvent les communautés amérindiennes et inuit).

\section{TOURISME VS CULTURE}

Il est permis d'affirmer d'emblée que la distinction entre tourisme tout court et tourisme culturel est très hasardeuse. L'auteur de ces lignes se souvient que son grand-père, parallèlement à ses activités traditionnelles de trappe, servait aussi de guide à des expéditions de chasse et de pêche. Le tourisme était déjà pour lui une industrie saisonnière, plus lucrative que la fourrure qui n'aurait pu à elle seule amener un revenu suffisant à la famille ; il lui permettait aussi, indirectement, de poursuivre la vie traditionnelle en forêt durant les mois d'hiver. Et c'est justement cette connaissance intime de la nature, appartenant pleinement à la tradition amérindienne, qui faisait de lui un homme hautement apprécié par les touristes chasseurs et pêcheurs.

Ce type de tourisme dit sportif continue de jouir d'une grande popularité et plusieurs communautés ont développé des services de pourvoirie. Il s'agit d'une tentative d'intégration des savoirs ancestraux à une activité bien contemporaine où le touriste, bien que ce ne soit pas là son objectif premier, entre en contact avec certains aspects des cultures aborigènes.

Mais aujourd'hui, à part l'amateur de gibiers dont les besoins et les attentes sont bien connus, qui sont les touristes qui veulent séjourner et voyager parmi les populations autochtones ?

Nature rimant avec aventure, les voyages tumultueux en canot sur les eaux vives ou en traîneau sur les espaces enneigés sont apparus comme des produits à développer dans les communautés amérindiennes et inuit. Il y a sûrement là un secteur d'investissement intéressant, mais il faut se rappeler qu'il s'agit d'un secteur fort concurrentiel où le consommateur d'émotions fortes bénéficie d'un choix considérable d'options qui vont de la planche à voile au rafting, en passant par le del- taplane, l'alpinisme, et bien d'autres encore. Dans un tel contexte, celui optera pour un séjour parmi les Premières Nations le fera d'abord et avant tout parce que la spécificité autochtone de l'offre touristique aura influencé son choix. Voilà donc le noud de la question !

\section{MYTHE VS RÉALITÉ}

On connaît l'histoire des enfants atikamekw qui croisent des touristes européens. «Vous êtes bien des Indiens ? * demandent les premiers. « Oui », répondent les enfants. " Mais vous n'avez pas de plumes ! $n$ s'exclament les touristes. « Nous sommes des Indiens, rétorquent les enfants, pas des oiseaux ! *

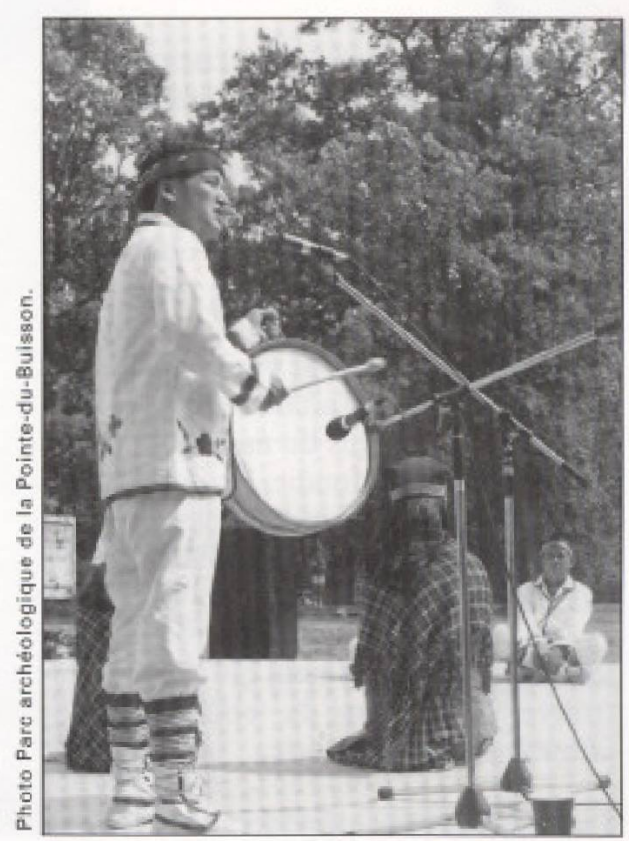

Spectacle de musique traditionnelle innu. 


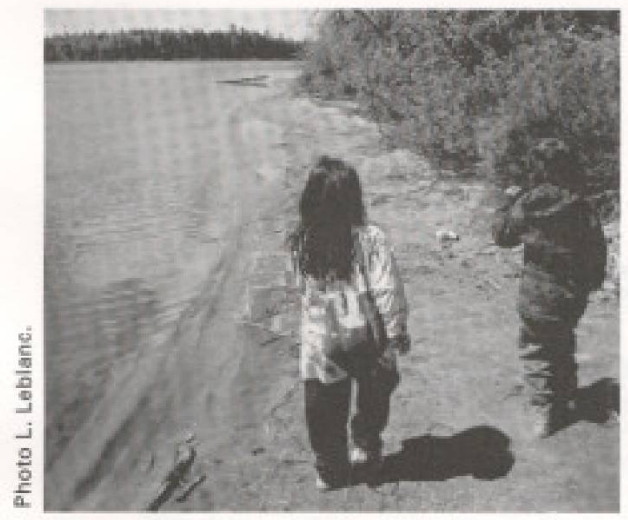

Enfants atikamekw.

En effet, l'homme n'est pas un oiseau, comme l'affirmait le titre d'un film, mais n'empếche que certaines images qui ont cours dans l'imaginaire des foules (qui aiment bien rêver et le rêve, justement, se vend très bien) font de nous des êtres capables de marcher au-dessus des arbres. Une simple visite dans une communauté autochtone et il y a de quoi tomber de haut !

Dans le jeu de l'offre et de la demande touristique, d'un côté il y a donc le mythe, vision * rousseauiste $*$ du bon sauvage, et de l'autre, la réalité actuelle qui entraînera inévitablement déceptions et regrets chez le voyageur. Cette vue apparaît toujours un peu simpliste, d"autant plus que ceux qui se font des gorges chaudes de la naivveté des touristes européens sont généralement eux-mêmes bien lotis en préjugés et en idées fausses sur leurs voisins des Premières Nations !

D'ailleurs, quel voyage touristique n'est pas, en bout de ligne, la poursuite d'un mythe? Venise, Athènes, le Sahara... la liste des destinations où le voyageur recherche les traces d'un passé, vu à travers les filtres du romantisme, et où l'actualité a très peu à voir avec le naguère et l'autrefois, est interminable. Les autochtones d'Amérique font vraiment rêver et la vision qu'on se fait de leur passé glorieux tient bien plus du merveilleux que de l'analyse approfondie. Il n'en convient pas moins de réaffirmer que les Amérindiens et les Inuit d'aujourd'hui sont bel et bien legataires de leur propre histoire et que l'époque légendaire n'est pas si lointaine historiquement qu'on ne puisse trouver de témoins du temps de la vie nomade sur le territoire.

En terme de développement touristique, la logique du marketing doit ici être dé- passée au nom d'une logique de la rencontre et de la découverte. Découvrir, c'est précisément rencontrer ce que l'on $n$ 'attendait pas. Au voyageur, nous pouvons offrir ce que nous sommes, oh̀ nous sommes, rien de plus. L'authenticité d'une rencontre avec la réalité amérindienne peut détromper celui qui arrive avec des idées surfaites mais ne devrait pas pour autant le décevoir (plusieurs récits de voyage peuvent en témoigner). C'est sur ces bases qu'on pourra bâtir des programmes d' intervention et de promotion en matière de tourisme qui tiendront à la fois compte de ce que nous avons été, de notre insertion dans le présent et de nos projets pour le futur de nos nations.

\section{FOLKLORE VS MODERNITÉ}

Le folklore est par définition un produit contemporain; il est le regard que la mémoire pose sur des arts populaires qui ont vu le jour à une autre époque. Nous nous actualisons aussi par ce que nous choisissons de répertorier et de conserver parmi les arts et les métiers de nos ancêtres.

Le powwow serait un emprunt à la culture des Amérindiens des plaines ; il en devient donc, dès qu'il est organisé dans l'Est, suspect d'inauthenticité. Si la polenta sauce tomate (plat typiquement amérindien) peut aujourd'hui passer, sans qu'on en rie, pour un plat sicilien, il serait pour le moins curieux qu'on reproche aux nations amérindiennes de faire quelques emprunts culturels entre elles. Au-delà des plumes et des panaches, le powwow est une expression d'amitié et de fierté en même temps qu'une occasion de rencontre. II fait revivre les rassemblements estivaux qui avaient lieu autour des points de traite et qui donnaient lieu à des réjouissances et à des retrouvailles.

Dans le mềme esprit, le festival d'été Présence autochtone ne craint pas de mêler les genres et les styles. Ainsi, sur la place Berri, en plein cour de Montréal, des tentes et des tipis s'érigent entre les tours de bétons. A côté de l'artisanat traditionnel (capteurs de rêves, mocassins perlés, etc.) qui s'offre à la vue du chaland, on y trouvait, en juin dernier, des peintres contemporains qui oeuvraient en public ; le soir, des projections de films en plein air complétaient le programme. $\mathrm{C}^{\text {t }}$ est ce type de côtoiement de formes et d'activités variées qui rend le mieux le foisonnement culturel des communautés autochtones et où s'abolit la frontière que des esprits trop cartésiens voudraient mettre entre passé et présent.

Le groupe Kashtin, mondialement connu, représente à lui seul cette synthèse : le rock et les langues ancestrales, la guitare électrique et l'univers autochtone. Le seul fait que le célèbre duo ait connu la carrière mondiale que l'on sait prouve justement que la culture actualisée des Amérindiens peut toucher le coeur des gens partout dans le monde (et non pas les décevoir comme certains esprits chagrins, évoqués plus haut, le laissent supposer).

Puisqu'il est question des plus fameux Innu de Mani-Utenam, il faut aussi mentionner, parmi les événements culturels de première importance, le pop festival Innu Nikamu qui revient tous les mois d'août dans cette sympathique communauté du Nitassinan.

Avant d'être un produit touristique, Innu Nikamu, comme les autres événements culturels autochtones, est d'abord et avant tout conçu pour consommation locale; n'est-ce pas là une garantie d'authenticité qui devrait satisfaire le touriste le plus exigeant ?

\section{MÉTROPOLE VS RÉGIONS}

La rivalité entre Montréal et les autres régions du Québec n'appartient pas comme telle au monde autochtone. Au contraire, il semble qu'il y a dans les manifestations culturelles autochtones montréalaises un exemplaire modèle de coopération et d'échange entre métropole et régions qu'on aimerait voir se reproduire dans d'autres domaines.

Le salon du plein air, le festival Présence autochtone et le powwow du Centre d'amitié autochtone de Montréal constituent des occasions uniques de faire valoir les ressources artistiques, culturelles et touristiques des communautés ; cellesci y délèguent toujours des représentants. Ainsi, on est venu à considérer Montréal comme un avant-poste des communautés et les autochtones urbains qui organisent les manifestations comme des agents de liaison. Ce qu'ils recherchent quand ils font leur promotion dans la métropole, c'est la visibilité et le rayonnement médiatique dont les produits touristiques, les 


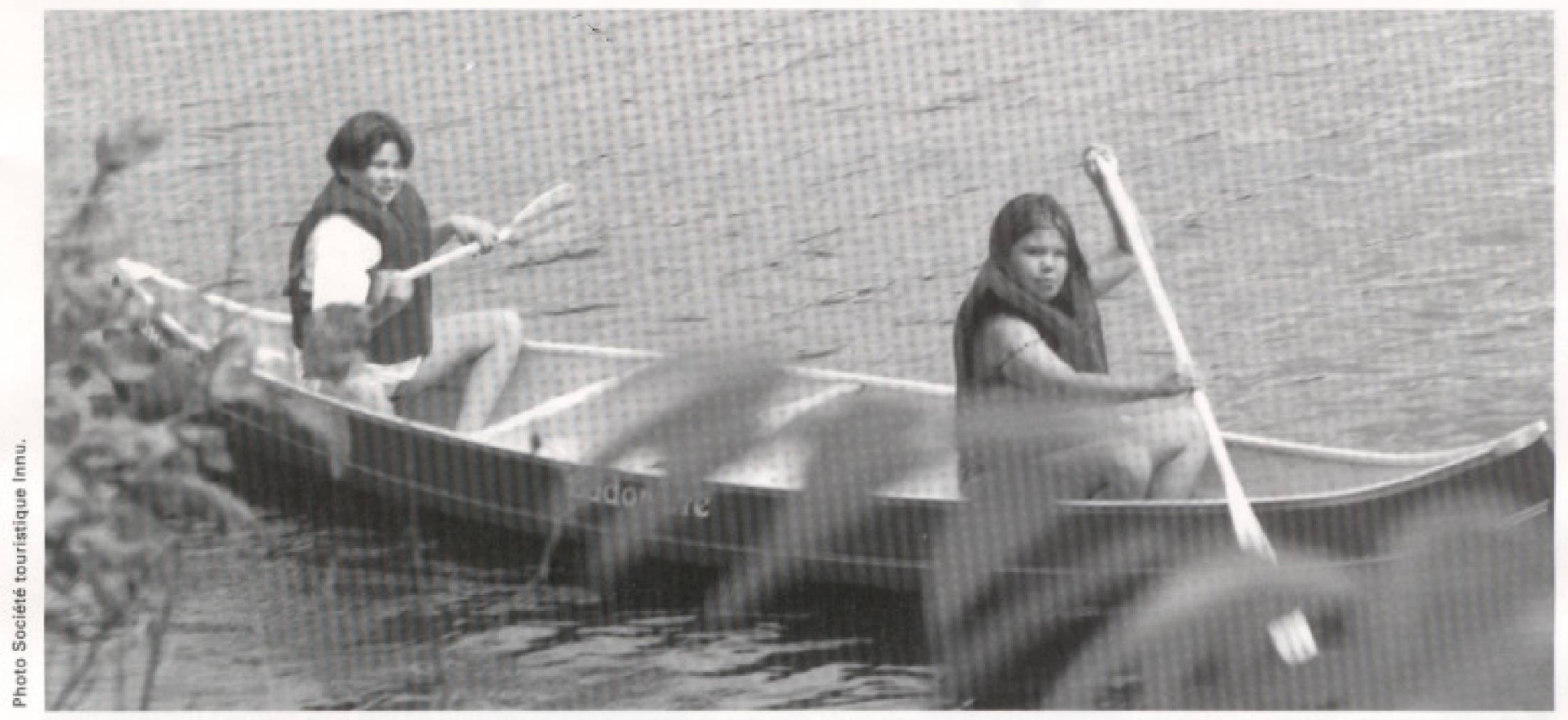

Tourisme autochtone pour les jeunes.

groupes artistiques ou les festivités locales bénéficient alors. Ces manifestations culturelles montréalaises ont encore un fort potentiel de croissance et pourront dans l'avenir - les promoteurs s' $y$ activent - jouer un rôle de plus en plus important dans le développement touristique. Le projet qui apparaît le plus prometteur en ce sens vise la création d'un lieu permanent de diffusion des cultures autochtones dans la métropole.

Cependant, une certaine crainte diffuse se fait jour ; le fait d'avoir accès aux cultures amérindiennes dans la cité pourrait-il aller jusqu'à assouvir la curiosité des visiteurs au point de leur faire abandonner l'idée de voyager dans les communautés ? Pas plus qu'un Chinatown ne saurait être un obstacle au tourisme en Chine, une activité autochtone dans le centre ne pourra entraver le développement du tourisme en région. En effet, il ne faut pas méjuger la force d'attraction que représente, pour une personne qui s'attache aux cultures amérindiennes et inuit, les communautés d'origine de ces cultures. Un premier pas en entraînant presque toujours un second, la curiosité incitera celui qui aura eu un avant-goût des réalités aborigènes à pousser plus loin ses investigations et l'amènera inévitablement dans l'un ou l'autre des territoires autochtones.

Enfin, rappelons-le, Montréal est aussi un territoire amérindien. Île surmontée d'une montagne, là où les systèmes fluviaux se croisent, c'est un lieu de rencontre millénaire qui porte en lui toute la magie de l'Amérique précolombienne. C'est ici qu'a été signée la Grande Paix de 1701 par les ambassadeurs de toutes les nations du continent ; c'est encore ici que sera souligné en 2001, par une grande fête, le tricentenaire de cet événement historique. Cette ouverture de la ville sur le monde est une vocation qui a d'abord été reconnue à ce bout de terre par les ancêtres des Amérindiens d'aujourd'hui ; et les efforts visant à rendre manifeste l'empreinte amérindienne sur ce lieu historique s'inscrivent pleinement dans la démarche en cours vers la pleine reconnaissance de nos nations.

\section{CONCLUSION}

Le touriste veut se trouver en contact avec 1'histoire vivante où vibrent les échos du passé et où se dessinent les visions de l'avenir. Le Québec d'aujourd'hui est le résultat d'une rencontre séculaire où des peuples ont conclu des alliances, ont effectué des échanges, ont appris les uns des autres. Cette histoire se poursuit aujourd'hui avec des collaborations concrètes et des difficultés de parcours auxquelles l'actualité attache parfois trop d'importance au détriment d'une vision qui tiendrait compte des tendances profondes de nos sociétés. Les cultures amé- rindiennes et inuit, caractérisées par le goût de l'échange et du commerce, appartiennent depuis toujours à ce pays qui a tant à offrir au visiteur. Le progrès du tourisme en territoire autochtone profite à l'ensemble de l'industrie par ses retombées, notamment en terme d'augmentation de l'achalandage dans les transports, l'hôtellerie et la restauration. Le tourisme peut rapporter beaucoup, dit-on. S'il permet à ceux qui partagent aujourd'hui cette terre de reconnaitre les racines communes de leur amitié et leur donne l'occasion de progresser coude a coude dans des echanges fructueux avec le reste de la planète, sa contribution aura en effet été inestimable.

L'auteur est directeur des activités culturelles a TERRES EN VUES, sociéré pour la diffusion de la culture autochtone. A ce titre, il coordonne la programmation du festival montréalais annuel Présence autochtone qui met en valeur les produits culturels des Premières Nations de toutes les Amériques. Engagé activement dans la communauté autochione de Montréal, il participe à des projets qui auront des répercussions importantes aux plans culturel et touristique : la celebration du tricentenaire de la Grande Paix de Montréal (1701-2001) et l'implantation d"une future maison des cultures amérindiennes et inuit dans la métropole québécoise.

Un comité de lecture a lu et accepté ce texte 